\title{
Miastenia Gravis em associação à Dermatomiosite e Doença de Graves: relato de caso
}

\author{
Myasthenia Gravis associated with Dermatomyositis and Graves Disease: \\ case report
Miastenia Gravis asociada a Dermatomiositis y Enfermedad de Graves: reporte de caso \\ Marina Coimbra da $\mathbf{C R U Z}^{1}$ \\ Gabriel Pina PAIVA \\ ${ }^{1}$ Graduanda do Curso de Medicina da Universidade Brasil, Campus Fernandópolis - 15600-000 Fernandópolis-SP, Brasil \\ ${ }^{2}$ Médico Neurologista. Docente do Curso de Medicina da Universidade Brasil, Campus Fernandópolis
}

15600-000 Fernandópolis-SP, Brasil

\begin{abstract}
Resumo
Miastenia Gravis é uma desordem da junção neuromuscular resultante de um processo autoimune, caracterizada por fatigabilidade fraqueza muscular que piora ao longo do dia e melhora com repouso. O propósito deste trabalho foi relatar um caso clínico de uma paciente com quadro de Miastenia Gravis associado a outras doenças autoimunes - Doença de Graves e Dermatomiosite. Paciente sexo feminino, 12 anos, iniciou quadro de fraqueza proximal, alterações cutâneas e perda ponderal significativa. Investigação diagnóstica demonstrou alterações dos hormônios tireoidianos e dosagem positiva de anticorpo antimicrossomal, levando ao diagnóstico de Doença de Graves, a qual foi tratada com radioiodoterapia. Durante a investigação fora detectada ainda elevação da creatinoquinase, eletroneuromiografia com padrão miopático e biópsia característica de miopatia inflamatória, sendo tratada com prednisona e manteve-se em remissão da doença. Aos 19 anos, paciente foi internada com quadro fraqueza flutuante da musculatura bulbar, e após nova investigação foi diagnosticada com Miastenia Graves através da dosagem positiva para anticorpos antirreceptor de acetilcolina. A tomografia computadorizada de tórax realizada evidenciou imagem sugestiva de timoma, sendo submetida à timectomia. Atualmente, apresenta estabilidade clínica de todas as suas comorbidades. Conclui-se que a associação da Miastenia Gravis a outras doenças autoimunes é frequente, sendo, portanto, recomendada a investigação quando houver suspeita clínica.

Descritores: Miastenia Gravis; Dermatomiosite; Doença de Graves; Doenças Autoimunes.
\end{abstract}

\section{Abstract}

Myasthenia Gravis is a neuromuscular junction disorder resulting from an autoimmune process, characterized by fatigability - muscle weakness that worsens throughout the day and improves with rest. The purpose of this study was to report a clinical case of a patient with Myasthenia Gravis associated with other autoimmune diseases - Graves' disease and Dermatomyositis. A 12-year-old female patient initiated proximal weakness, skin changes, and significant weight loss. Diagnostic investigation showed changes of thyroid hormones and positive dosage of antimicrosomal antibody, leading to the diagnosis of Graves' Disease, which was treated with radioiodine therapy. During the investigation, there was still elevation of creatinine kinase, electroneuromyography with myopathic pattern and biopsy characteristic of inflammatory myopathy, being treated with prednisone and remaining in remission of the disease. At age 19, patient was hospitalized with a fluctuating weakness of the bulbar musculature, and after a new investigation was diagnosed with Myasthenia Graves through the positive dosage for acetylcholine anti-receptor antibodies. Computed tomography of the chest revealed an image suggestive of thymoma, being submitted to thymectomy. Currently, it presents clinical stability of all its comorbidities. It is concluded that the association of Myasthenia Gravis with other autoimmune diseases is frequent and, therefore, the investigation is recommended when there is clinical suspicion.

Descriptors: Myasthenia Gravis; Dermatomyositis; Graves Disease; Autoimmune Diseases.

\section{Resumen}

Miastenia Gravis es una desorden de la unión neuromuscular resultante de un proceso autoinmune, caracterizado por fatiga debilidad muscular que empeora a lo largo del día y mejora con reposo. El propósito de este trabajo fue relatar un caso clínico de una paciente con cuadro de Miastenia Gravis asociado a otras enfermedades autoinmunes - Enfermedad de Graves y Dermatomiositis. Paciente sexo femenino, 12 años, inició cuadro de debilidad proximal, alteraciones cutáneas y pérdida ponderal significativa. La investigación diagnóstica demostró alteraciones de las hormonas tiroideas y dosificación positiva de anticuerpos antimicrosomal, llevando al diagnóstico de Enfermedad de Graves, la cual fue tratada con radioiodoterapia. Durante la investigación se detectó aún elevación de la creatinoquinasa, electroneuromiografía con patrón miopático y biopsia característica de miopatía inflamatoria, siendo tratada con prednisona y se mantuvo en remisión de la enfermedad. A los 19 años, paciente fue internada con cuadro debilidad flotante de la musculatura bulbar, y después de una nueva investigación fue diagnosticada con Miastenia Graves a través de la dosificación positiva para anticuerpos antirreceptor de acetilcolina. La tomografía computarizada de tórax realizada evidenció una imagen sugestiva de timoma, siendo sometida a la timectomía. Actualmente, presenta estabilidad clínica de todas sus comorbilidades. Se concluye que la asociación de Miastenia Gravis a otras enfermedades autoinmunes es frecuente, por lo que se recomienda la investigación cuando hay sospechas clínicas.

Descriptores: Miastenia Gravis; Dermatomiositis; Enfermedad de Graves; Doenças Autoimunes.

\section{INTRODUÇÃO}

Miastenia Gravis (MG) é uma desordem da junção neuromuscular (JNM) em que auto-anticorpos atuam contra os receptores de acetilcolina (AchR) ou o receptor tiroquinase músculo específica (Anti-MuSK) $)^{1-3}$.

Sua prevalência tem aumentado nos últimos anos, estando entre 2 a 7 para cada 10.000 indivíduos, e sua taxa de incidência média é de 5,3 novos casos anuais para cada um milhão de pessoas ${ }^{3,4}$. Embora possa acometer indivíduos de qualquer idade e ter predileção pelo sexo feminino (razão de 3:1), apresenta pico de manifestação bimodal envolvendo mulheres na terceira e quarta décadas e homens na sexta e sétima décadas da vida ${ }^{4}$.

Os pacientes apresentam fraqueza com fatigabilidade em grupos musculares específicos. A fraqueza flutua dia a dia, piorando com atividade e melhorando com repouso. Comprometimento ocular - ptose e/ou diplopia - geralmente é o sintoma inicial. A progressão da doença geralmente ocorre nos dois primeiros anos da doença, podendo acometer musculatura facial, mastigatória, orofaríngea, apendicular e respiratória ${ }^{4}$.

O diagnóstico é baseado na dosagem de autoanticorpos e reforçado por evidências de anormalidade da junção neuromuscular - boa resposta ao anticolinesterásico ou testes eletrofisiológicos - eletroneuromiografia (ENMG) com estimulação repetitiva com decremento anormal ou eletromiografia de fibra única com jitter aumentado ${ }^{1,4}$. 


\section{CASO CLÍNICO}

Paciente do sexo feminino, solteira, nuligesta, estudante de engenharia civil, aos 12 anos iniciou quadro de dificuldade em subir escadas, pentear cabelos e alterações cutâneas, além de perda ponderal de $15 \mathrm{~kg}$. Durante investigação realizou os exames descritos na Tabela 1.

Tabela 1. Resultados dos exames complementares realizados durante a investigação diagnóstica e manejo da paciente, nos dois momentos sintomatológicos

\begin{tabular}{|c|c|c|}
\hline DATA & EXAME & RESULTADO \\
\hline FEVEREIRO/2009 & $\begin{array}{c}\text { CK } \\
\text { Anticorpo } \\
\text { antimicrossomal } \\
\text { Anticorpo } \\
\text { tireoglobulina } \\
\text { ENMG }\end{array}$ & $\begin{array}{c}125 \mathrm{U} / \mathrm{L} \\
1300 \mathrm{UI} / \mathrm{ml} \\
97 \mathrm{Ul} / \mathrm{ml} \\
\text { Miopatia difusa com } \\
\text { sinais de atividade }\end{array}$ \\
\hline MARÇO/2009 & Biópsia muscular & $\begin{array}{l}\text { Fibras com variação } \\
\text { de calibre, atrofia } \\
\text { perifascicular }\end{array}$ \\
\hline ABRIL/2015 & $\begin{array}{c}\text { TSH } \\
\text { T4 livre } \\
\end{array}$ & $\begin{array}{c}4,66 \mu U \mathrm{Ul} / \mathrm{ml} \\
1,32 \mathrm{ng} / \mathrm{dl} \\
\end{array}$ \\
\hline JUNHO/2015 & $\begin{array}{l}\text { FAN } \\
\text { CK } \\
\text { VHS } \\
\end{array}$ & $\begin{array}{c}\text { Pontilhado fino } \\
\text { denso } 1 / 60 \\
26 \mathrm{U} / \mathrm{L} \\
11 \mathrm{~mm} / \mathrm{h} \\
\end{array}$ \\
\hline JULHO/2015 & $\begin{array}{c}\text { ENMG } \\
\text { Anticorpo } \\
\text { Antirreceptor de } \\
\text { acetilcolina } \\
\text { Tomografia de tórax }\end{array}$ & $\begin{array}{c}\text { Bloqueio pós- } \\
\text { sináptico da junção } \\
\text { neuromuscular } \\
4,90 \mathrm{UI} / \mathrm{ml} \\
\text { Aumento das } \\
\text { dimensões do timo }\end{array}$ \\
\hline
\end{tabular}

Devido aos achados da história e do exame físico, além dos achados complementares - fraqueza com padrão de cinturas, elevação de CK (creatinouinase), e ENMG com padrão miopático foi aventada hipótese de miopatia, sendo realizada biópsia muscular a qual evidenciou presença de variação de calibre de fibras musculares e atrofia perifascicular - achado característico de Dermatomiosite (DM). Foram detectadas ainda alterações dos hormônios tireoidianos e dosagem positiva do anticorpo antimicrossomal, estabelecendo o diagnóstico de Doença de Graves (DG).

Como tratamento da Doença de Graves foi submetida a iodoterapia, evoluindo com hipotireoidismo, o qual foi corrigido com reposição de levotiroxina. Recebeu ainda Prednisona $50 \mathrm{mg}$ por dia como tratamento da Dermatomiosite.

Aos 19 anos, iniciou um quadro dificuldade de mastigação principalmente ao final das refeições, disfagia para sólidos e líquidos - apresentando inclusive episódio de regurgitação nasal de líquido, além de alteração na fonação. Sintomas mais intensos ao final do dia. Cerca de quatro meses após o início das queixas, a paciente foi internada com piora progressiva dos sintomas. Devido ao quadro de fraqueza de grupos musculares específicos de caráter flutuante, foi feita a hipótese diagnóstica de Miastenia Gravis. Iniciou-se Piridostigmina $60 \mathrm{mg} 3$ vezes ao dia como prova terapêutica e apresentou melhora parcial dos sintomas. Ao exame neurológico, disartria leve, ptose palpebral à esquerda, diparesia facial e fraqueza bilateral e simétrica do ileopsoas $(4+/ 4+)$, além de teste de fadigabilidade positivo. Realizou novos exames laboratoriais e complementares - também descritos na Tabela 1. Com relação a medicação, manteve-se a Piridostigmina $60 \mathrm{mg} 3$ vezes ao dia, além de prednisona 40 $\mathrm{mg} / \mathrm{dia}$.

A suspeita clínica foi confirmada com a presença de auto anticorpos antireceptor de acetilcolina e reforçada pela demonstração ao estudo eletrofisiológico de anormalidade pós-sináptico da junção neuromuscular com ENMG com decremento anormal e Eletromiografia de fibra única com jitter prolongado. Durante a investigação, realizou-se também tomografia computadorizada de tórax que evidenciou imagem sugestiva de timoma. Após um mês, paciente foi submetida a timectomia por vídeo, sendo que o estudo anatomopatológico do órgão revelou hiperplasia folicular.

Atualmente, paciente refere pouca limitação das atividades diárias, mantendo ao exame físico apenas fraqueza discreta em face e musculatura de cintura pélvica, além de ptose bilateral (após teste de fatigabilidade). Apresenta quadro estável de todas as suas comorbidades - Miastenia Gravis, Dermatomiosite e hipotireoidismo pós iodoterapia com o uso de Piridostigmina $60 \mathrm{mg}$ 5-6 vezes/dia; prednisona em titulação de dose para redução por ganho de peso $(3,7 \mathrm{~kg}$ em 4 meses) visando chegar a $40 \mathrm{mg}$ em dias alternados; azatioprina 3 comprimidos diários; Puran $100 \mathrm{mcg} / \mathrm{dia}$, além de reposição de cálcio e vitamina D.

\section{DISCUSSÃO}

MG é um distúrbio neuromuscular que envolve a formação de auto-anticorpos contra a porção pós-sináptica da JNM, cursando com fraqueza e fatigabilidade flutuante de grupos musculares específicos ${ }^{1,4}$. Pode representar achado único ou associar-se a outras doenças autoimunes, em especial as da tireoide. Dessa forma, ao se confirmar MG é interessante que se verifique a função tiroidiana, além da realização de outros testes sorológicos para patologias autoimunes caso haja indicação clínica ${ }^{1,5}$.

A prevalência de condições autoimunes tireoidianas é maior nos pacientes com MG do que na população em geral, com destaque para o hipertireoidismo, cuja taxa de associação pode chegar a $3 \%$. Assim como a maioria dos casos descritos na literatura, descrevemos um caso em que o diagnóstico da Doença de Graves, principal causa de hipertireoidismo autoimune, antecedeu o de MG. Tais condições compartilham a predileção pelo sexo feminino e apresentam prognóstico variável quando adjuntas, sendo que na maioria dos casos se verifica uma melhora do quadro da MG com piora da Doença de Graves. A associação DG-MG requer cuidados no manejo do hipertireoidismo, uma vez que seu tratamento pode acarretar em crises de miastenia que ameaçam a vida do paciente ${ }^{5}$. No presente caso, não houve influências na evolução ou na conduta do quadro da paciente, uma vez que seu diagnóstico de Doença de Graves precedeu em 7 anos o quadro de $\mathrm{MG}$, de forma que, durante este intervalo, o hipertireoidismo foi corrigido com iodoterapia levando a um hipotireoidismo antes da concomitância diagnóstica com MG.

Outra possível associação autoimune a MG, embora mais rara e menos relatada, é a dermatomiosite, que consiste em uma miopatia inflamatória com manifestações cutâneas, decorrente de autoimunidade. Sua característica principal também é fraqueza muscular, no entanto, ao invés de ser flutuante e acometer principalmente a musculatura ocular e proximal como na MG, é constante e acomete mais o tríceps e o quadríceps. Um diagnóstico diferencial dessas duas patologias é imprescindível, devido a semelhança clínica das duas e às consequências terapêuticas resultantes. Disfagia é sintoma que pode estar presente em ambas as patologias, quando há acometimento da musculatura bulbar ${ }^{6-8}$.

A principal implicação terapêutica desta associação diz respeito ao uso de corticoterapia: na miosite recomenda-se início com altas doses de esteroides com posterior titulação; enquanto que na MG, devido ao risco de exacerbação dos sintomas miastênicos com doses altas de corticoide, recomenda-se maiores cuidados ao introduzir corticoide em doses elevadas ${ }^{6,8}$.

Diante de um quadro de MG é coerente a realização de uma tomografia de tórax para a investigação do timo, devido ao fato de que, em até $20 \%$ dos casos, uma concomitância da miastenia com timoma se faz presente, com indistinção entre os sexos e podendo acometer qualquer faixa etária, embora o 
pico de apresentação seja na quinta década de vida. Nestes pacientes, o quadro miastênico tende a ser mais severo ${ }^{1,9}$.

$\mathrm{Na}$ ausência de timoma, a timectomia está indicada nos casos mais graves - refratários ou intolerantes ao tratamento clínico, ou objetivando reduzir a dose e/ou duração da imunoterapia ${ }^{10}$. No entanto, se houver suspeita ou confirmação de timoma, a cirurgia passa a ser obrigatória. Tal procedimento é indicado para a resolução do tumor e não da Miastenia, logo pode não afetar o quadro miastênico, embora pareça trazer benefícios a cerca de $75 \%$ dos pacientes com Miastenia Gravis - possível melhora ou estabilização da doença, conquanto demoram, na maioria das vezes, pelo menos um ou dois anos de pós-cirúrgico para serem notadas ${ }^{1,}$ 3, 9, 10. Vale ressaltar que a timectomia não representa uma urgência, devendo, portanto, ser concretizada apenas a posteriori da estabilização da $\mathrm{MG}$, removendo todo o tecido do timo, com posterior classificação histológica ${ }^{1,10}$. A paciente em questão, conforme as recomendações, foi submetida ao exame tomográfico do timo, que evidenciou aumento do órgão, sugerindo timoma, sendo, portanto, realizada a timectomia por vídeo.

\section{CONCLUSÃO}

A Miastenia Gravis, em se tratando de uma doença autoimune, pode associar-se a outras patologias que despertam a autoimunidade - como a Doença de Graves e dermatomiosite. Assim, recomenda-se uma investigação ampla de outras condições autoimunes a partir do diagnóstico de MG ou o oposto - interrogar e investigar um possível quadro de MG diante de um paciente com fraqueza flutuante na vigência de alguma outra doença autoimune. Em especial, realizar um diagnóstico diferencial entre MG e dermatomiosite, visto que ambas cursam com fraqueza muscular, no entanto, sempre considerando que uma associação de ambas, embora infrequente, pode se fazer presente e trazer implicações na conduta terapêutica do quadro.

\section{REFERÊNCIAS}

1. Meriggioli MN, Sanders DB. Autoimmune myasthenia gravis: emerging clinical and biological heterogeneity. Lancet Neurol. 2009; 8(5):475-90.

2. Kauling ALC, Almeida MCS, Locks GF, Brunharo GM. Miastenia Gravis: Relato de Dois Casos e Revisão da Literatura. Rev Bras Anestesiol; 2011; 61(6):755-63.

3. Binks S, Vincent A, Palace J. Myasthenia gravis: a clinical-immunological update. J Neurol; 2016; 263(4):826-34

4. Drachman DB. Miastenia Gravis e Outras Doenças da Junção Neuromuscular. In: Hauser SL, Josephson SA. Neurologia clínica de Harrison. 3. Ed (Edição Digital). Porto Alegre: AMGH; 2015. p. 468-474.

5. Pouye A, Dia DG, Ndongo S, Faye A, Sakho ND and Ndiaye FSD. Grave's disease associated with myasthenia gravis: a case report. Internal Medicine Inside. 2014; 2(1):4.

6. Gómez CS, Robles BJF, Perles CM, Barbadillo C, Godoy H, Andréu JL. Dermatomyositis and Myasthenia Gravis: An Uncommon Association with Therapeutic Implications. Reumatol Clin. 2015; 11(4):244-6.

7. Ortigosa LCM, Reis VMS. Dermatomiosite. An Bras Dermatol. 2008; 83(3):247-59.

8. Paik JJ, Corse AM, Mammen AL. The Co-Existence of Myasthenia Gravis in Patients with Myositis: A Case Series. Semin Arthritis Rheum. 2014; 43(6):792-6.

9. Zenón TG, Silva JAV, Hinojosa HR. Miastenia gravis: caso clínico y revisión de la bibliografia. Med Int Mex. 2011;27(3):299-309.
10. Sanders DB, Wolfe GI, Benatar M, Evoli A, Gilhus NE, Illa $\mathrm{I}$, et al. International consensus guidance for management of myasthenia gravis: Executive summary. Neurology. 2016; 87(4):419-25.

\section{CONFLITO DE INTERESSES}

Os autores declaram não haver conflitos de interesse.

\section{AUTOR PARA CORRESPONDÊNCIA}

\section{Gabriel Pina Paiva}

gabrielneurologia@hotmail.com 